\title{
Espaço vivido e espaço mental: Dalton Trevisan e a dicotomia social do urbanismo curitibano
}

Nelson H. Vieira ${ }^{1}$

Em parte o efeito psicológico, em parte o direito de desconfiar que os homens exercem perante o corre-corre da vida metropolitana, nos obrigam a sermos reservados. [...] o aspecto interior desta reserva exterior não é somente indiferença mas, mais do que apercebemos, é uma aversão mínima, um estranhamento e uma repulsão mútuos que arrebentarão em ódio e luta no momento de contato mais próximo.

Georg Simmel, The metropolis and mental life

Curitiba toda catita do primeiro mundo - com essa população de quarto mundinho?

Curitiba - essa grande favela do primeiro mundo.

Curitiba é uma boa cidade se você for a barata leprosa e pálida de medo.

Dalton Trevisan, Pico na veia

Curitibanos não moram em parques públicos como os cariocas nas praias do Rio de Janeiro. Eles são um bando sombrio de imigrantes europeus orientais, alemães e japoneses misturados com a local cultura gaúcha.

Jeb Grugman. Welcome to the urban revolution: how cities are changing the world

As narrativas críticas e mordazes de Dalton Trevisan manifestam igualmente riso, gozo e compaixão perante as vicissitudes dos seus Joões e Marias, vivendo numa Curitiba com a reputação contraditória de "primeiro mundo" e "quarto mundinho". Como se explica esse paradoxo que obscurece a visão de uma cidade "inscrita" com paixão e obsessão? Por que é que Dalton Trevisan decidiu comprometer toda a sua vida e obra com a finalidade de "ler" e reler continuamente esse espaço urbano? Por ódio, vingança, desprezo ou malícia? Certamente não. O projeto trevisaniano revela outros interesses que têm mais a ver com a condição humana

\footnotetext{
${ }^{1}$ Doutor em literatura brasileira e portuguesa, professor do Department of Portuguese \& Brazilian Studies da Brown University, Providence, RI, Estados Unidos. E-mail: nelson_vieira@brown.edu
} 
numa situação urbana do que aponta uma mera crítica do tratamento tautológico dos seus contos. ${ }^{2}$

Este ensaio pretende abordar a estética de Dalton Trevisan dentro do contexto do urbanismo com a finalidade de mostrar não somente como o escritor dá voz e visibilidade aos esquecidos e invisíveis mas como o projeto da modernidade para esses seres falhou por causa de mitos e ilusões urbanos. Na linha de Walter Benjamin e de sua "dialética de ver", Dalton Trevisan, com o seu estilo inovador e imediato, projeta o visual e a imagem para construir "imagens-pensantes" (Denkbilder de Benjamin), ${ }^{3}$ com o propósito de comunicar os aspectos viscerais do espaço vivido pela população de Curitiba a partir de diversas óticas - corrosivas e contundentes mas também cômicas e compassivas. Além desses objetivos, o ensaio se refere aos projetos originais de urbanismo implantados "mentalmente" por urbanistas locais no intento de melhorar e fortalecer a infraestrutura curitibana perante o espaço vivido por seus habitantes. Porém, a imagem do drama ontológico dos curitibanos dramatizados na obra trevisaniana parece desmentir o sucesso desse planejamento modernizante.

Sombrio, provinciano, lúgubre e reservado são adjetivos um tanto pejorativos frequentemente associados a Curitiba e aos curitibanos, porém, em 2007, Curitiba ocupou o terceiro lugar numa lista das "15 Cidades Verdes" do mundo e, em 1996, foi considerada a cidade mais inovadora do Brasil pela Conferência Habitat II. ${ }^{4}$ Transformada de uma província empobrecida de 350.000 habitantes em 1965 em uma metrópole de quase dois milhões em 2005, Curitiba é classificada hoje em dia no topo dos melhores padrões de vida do Brasil. É sabido que essa evolução admirável se deve aos esforços de muitos indivíduos e políticos, mas, sobretudo, ao ex-prefeito e arquiteto mestre Jaime Lerner, ao seu Grupo Lerner e ao Instituto de Pesquisa e Planejamento Urbano de Curitiba (IPPUC), estabelecido por Lerner em $1965 .{ }^{5}$ Segundo Lerner, a realização desse projeto urbano se assentou numa estratégia de "desenvolvimento incremental" e supostamente não a partir de um plano mestre totalmente preconcebido, que na terminologia do urbanismo planejado, segundo Henri Lefebvre, é

\footnotetext{
2 Todas as traduções do inglês para o português, a não ser quando indicado, são de Nelson H. Vieira, autor deste ensaio.

3 Graeme Gilloch refere-se ao termo Denkbilder para aludir à preocupação bejaminiana quanto ao visual e imagístico que aparecem consistentemente para evocar os cityscapes dos seus primeiros textos urbanos sobre grandes cidades como Moscou, Berlim e Nápoles (Gilloch, 1996, p. 18-19).

${ }^{4}$ Essa informação e as estatísticas seguintes foram tiradas do blog de David Ayers, disponível em: $<$ http://davidayers.wordpress.com/urban-planning-in-curitiba-brazil $>$.

5 Ver Jeb Brugmann (2009), capítulo 12, sobre Curitiba (p. 214-228).
} 
reconhecido como "espaço mental" ou abstrato em oposição ao "espaço vivido" ou real, social e urbano (Lefebvre, 2005, p. 355-356, 362-363). Por outro lado, o termo "mental life" empregado por Georg Simmel (1969) tem outro sentido e corresponde à mentalidade das pessoas que ocupam o "espaço vivido" definido por Lefebvre e não se refere ao espaço mental ou abstrato dos planejadores. ${ }^{6}$ Ao longo desta apresentação empregaremos "mental" nos dois sentidos - "espaço mental" e "vida mental", que na verdade são distintos. O "espaço mental" é planejado e preconcebido pelo urbanismo planejado e a "vida mental," segundo Simmel, representa a psique de pessoas residindo freneticamente nas grandes metrópoles.

No contexto de urbanismo, até certo ponto, Curitiba representa uma história de sucesso não somente por causa da sua infraestrutura modelo de transporte público mas também pela realização de um ecossistema eficiente e de despesa módica destinada a controlar os seus rios contra possíveis inundações. Por cima, entre 1965 e 1995, Curitiba foi também reconhecida como a cidade de crescimento mais rápido do Brasil, com o ritmo de urbanização três vezes mais do que a média mundial. Então, como se entende o satírico tratamento trevisaniano no qual Curitiba é uma "grande favela" e uma cidade vampiresca, predatória, violenta, perversa, e pobre - uma imagem ubiquamente dramatizada nas mais de 30 coletâneas de contos, haicais, poesia, aforismos, baladas, e crônicas escritos durante um período de cinquenta anos? Além disso, as narrativas trevisanianas deliberadamente dão enfoque à penúria econômica, a relações escabrosas, injustiça social e perigos urbanos, e, nesta linha, a comportamentos violentos manifestados por Joões e Marias das classes média-baixa e baixa, e também por seres marginais como criminosos e favelados vivendo num espaço urbano que não reflete os avanços dessa cidade "verde" e vibrante, evocada por urbanistas profissionais locais e internacionais. Se a obra de Dalton Trevisan, de 1959 até aos nossos dias, representa consistentemente, mas de uma forma diversificada e atualizada, uma singular e controversa expressão artística sobre uma perturbadora vivência urbana brasileira, somos obrigados a repensar a sua comédia humana em face ao desenvolvimento fenomenal dessa cidade "modelo" projetada para o Brasil e o mundo inteiro.

Talvez uma das pistas para decifrar esse quebra-cabeça ou dicotomia social e literária esteja enterrada na época da sua primeira coletânea de 1959, Novelas nada exemplares, com o seu título paródico inspirado por

\footnotetext{
${ }^{6}$ Aliás, o termo "mental space", em inglês, tem diversos significados no campo de planejamento urbano, dependendo da escola de urbanização que se siga. Para efeito deste texto, ficamos com a terminologia de Lefebvre.
} 
Cervantes. Pois Dalton Trevisan é um escritor "nada exemplar", sobretudo no seu desafio de fabular graficamente um conteúdo áspero/desagradável que no decorrer da sua carreira é agenciado por um experimentalismo cada vez mais inovador. Como aludido acima, as formas trevisanianas acabam sendo manifestadas por meio de narrativas paródicas, minimalistas, haicais perversos, "imagens pensantes", frases titilantes, poemas irônicos, diálogos sem narração, elipses calculadas, aforismos incisivos, contos recortados e retrabalhados, alguns minimamente diferentes - tudo isso com o objetivo de revelar comportamentos chocantes atrás de portas fechadas e às vezes até nas ruas. Nos anos 1950, Curitiba aparece na obra como uma cidade provinciana e ecologicamente desastrosa. Essa imagem é dramatizada dolorosamente no conto "Pensão Nápoles", na figura de um pobre coitado, tísico, fracassado, e sem futuro:

A salvação era casar, escapulir para o outro lado da cidade, onde o rio não chegasse - com as chuvas alagava os quintais, cobria os sapatos de lama, os sapos coaxavam na cozinha. Irrompia, sem aviso, sob os pés dos amantes distraídos. A prefeitura ignorava-lhe o curso subterrâneo; o rio de pobre, não fora o Belém, com que água as mães dariam nos piás o banho de sábado? (Trevisan, 1979, p. 47)

Irônica, satírica e profética, essa citação já apontava para um dos sérios problemas infraestruturais (de inundações) a ser mais tarde resolvido pelo Grupo Lerner, que, no entanto, não resolveria a questão da pobreza e do vício rompante para os futuros favelados nas vilas (favelas de Curitiba) evocado no conto "Isso aí, malandro" (Macho não ganha flor, 2006) sobre um pobre cara faminto, obrigado a ser ladrão: "A gente se enfia na casa arrombada. Tem uma pedra queimando por dentro. Grudados na tua nuca os mil olhos dos cagüetas da Vila. De repente dá uma fome desgracida. E você ataca direto a geladeira. Vinho tinto é uma boa" (Trevisan, 2006, p. 15). Apesar do roubo potencial, o leitor sente pena e compaixão pelo ladrão malnutrido. Pois o prazer bem passageiro de uma comidinha e um gole de vinho tinto suscita no leitor riso, já que a prioridade para aquele é comer, acima de roubar, o que evoca compadecimento. Da mesma coletânea, o conto "Um tal Tibinha", cujo título com o diminutivo já inspira uma certa afetividade, é narrado orgulhosamente pela ex-namorada de um malandro, esta vez chamado o "Curitiba", como se a malandragem representasse toda a cidade e esta fosse um lugar arriscado: "Acho mesmo que foram os drogados. Lá, o ninho dos maconheiros. Viver na Vila, cara, é muito perigoso. [...] Fatal. Acaba fazendo tudo o que ele manda. Até o que não quer. Esse meu Tibinha é de morte" (Trevisan, 2006, p. 29-30). 
Como contista aplaudido criticamente pelas suas narrativas astuciosamente construídas e como cronista imaginativo dos costumes das classes menos favorecidas e das figuras agressivas e vulneráveis dos seus dramas populares, Dalton Trevisan é ao mesmo tempo mal interpretado pelo grande público curitibano por causa de figuras, como o "tal Tibinha", que parecem macular a imagem criada pelos urbanistas da cidade. Esse público se sente ofendido porque reside numa cidade progressista em termos nacionais e elogiada no plano internacional por ser superverde. Nessa linha, o público curitibano se sente orgulhoso pelos avanços infraestruturais como o sistema de transportes bem organizado e extensivo e com um ecossistema funcional de primeiro mundo, entre outras obras públicas notáveis, como diversos parques para celebrar as variadas etnias que compõem a sociedade da cidade. Por outro lado, pergunta-se: os tais Tibinhas frequentam esses parques?

Dada a história notável de infraestrutura e sucesso apoiada pelos seus cidadãos orgulhosos, por que é que o mais famoso escritor de Curitiba e um dos mais talentosos contistas do Brasil e da América Latina invoca repetidamente o lado tenebroso do espaço vivido com suas múltiplas formas de violência brutal e erótica (violência física e "douce") na vida cotidiana dessa cidade ecologicamente vanguardista? Uma das respostas se assenta na diferença entre o espaço vivido (pelos habitantes) e o espaço mental planejado pelos urbanistas. Nas suas narrativas, Dalton Trevisan privilegia, com seu estilo imediato, o submundo do espaço para que o leitor lúcido vivencie o clima precário mas humano do estilo de vida dessas zonas da cidade. Para esse fim, o autor emprega gíria, linguagem coloquial e jornalística (com toques intertextuais de alusões eruditas, bíblicas, literárias e históricas), por via de vozes narrativas cínicas, lascivas, excluídas, cotidianas, espertas mas esquecidas. A recriar o coloquial, o cotidiano e a precariedade desse lado da vida, Trevisan se aproveita de diversos recursos:

Notícia policial, frase no ar, bula de remédio, pequeno anúncio, bilhete de suicida, o meu e o teu fantasma no sótão, confidência de amigo, a leitura dos clássicos etc. O que não me contam eu escuto atrás da porta. O que não sei eu adivinho - e com sorte você adivinha sempre o que, cedo ou tarde, acaba acontecendo (Trevisan, 1974, p. 9-10).

Essa citação famosa, tirada da sua minideclaração autobiográfica, "Vida e obra de Dalton Trevisan", incluída como prefácio para a sua coletânea O vampiro de Curitiba, de 1974, e interpretada como afirmação da sua estética, se assemelha ao comentário feito por Walter Benjamin no seu "Rua de mão única", em que observa que a (re)construção da vida cotidiana na literatura não pode se aproveitar de um simples contexto literário: 
Efetividade literária significativa somente pode ser realizada dentro de um intercâmbio preciso de fazer e escrever; ela necessita cultivar as formas não-espectaculares melhor acomodadas à sua influência em comunidades ativas do que ao gesto universal do livro, em panfletos, brochuras, artigos jornalistas e reclames. Somente tal linguagem imediata servirá como parelho (match) efetivo para o momento (Benjamin, 2008, p. 46).

Desse modo, Dalton Trevisan evoca as vidas parcas, dissolutas e insatisfeitas dentro de cenários tragicômicos de existência urbana marcada por aflições, injustiças, crimes e violência, sobretudo as contra mulheres: "Chega de noivo que se apaixona. Só querendo te matar. Ou morrer. Suicidar os dois. Tomara um que não goste de mim" (Trevisan, 1997, p. 33). Duro e brutal, o estilo trevisaniano não conta histórias abertamente moralistas porque inventa uma sangria e vitimização performativa de perversões predatórias e eróticas (psíquicas e culturais) com a principal finalidade de captar a aflição humanizante que geralmente é vista e tratada com abjeção. A sua abordagem sardônica e tragicômica desenterra hipocrisia e repressão social enquanto afetivamente dramatiza as táticas desesperadas de sobrevivência exercidas pelas classes marginalizadas. Esses crimes sensacionalistas, semelhantes aos das manchetes de uma imprensa marrom, são também retratados nas capas das suas coletâneas e até dentro das narrativas em que Dalton Trevisan e seus editores incluem a arte gráfica de diversos artistas nacionais e internacionais a fim de ilustrar marcadamente os hábitos e crimes dessas vítimas urbanas.

Perante a dicotomia entre o "espaço mental", delineado pelo urbanismo planejado de Curitiba, e o "espaço vivido" e evocado pelo olhar visionário e jocoso mas comovente de Dalton Trevisan, parece que a imagem literária do escritor destina-se a por no placo da vida o espaço social vivido pelo submundo curitibano ou, como Lefebvre prefere denominar, as "práticas espaciais", isto é, os "espaços representacionais". Assim, o leitor acaba sentindo pena pelo dano causado contra a cidade e os seus cidadãos esquecidos. Porém, pergunta-se: por que recorrer a uma sangria figurativa supostamente resultado do rastejar vampiresco que figurativamente devasta e estupra Curitiba? Que tipo de sangue corre nas veias dessas criaturas urbanas? E será justo continuar a apelidar o autor de "o vampiro de Curitiba", codinome que recebeu, a partir da sua coletânea eponímica e famosa, do público e da imprensa por causa da aversão trevisaniana à mídia local, nacional e internacional e também às relações públicas em geral?

Numa linha metafórica, os seus vampiros são criaturas da própria cidade e elas se alimentam e se mordiscam e atacam qualquer vítima vulnerável. 
Não são versões transilvanianas ou vitorianas provindo de mitos, folclore e literatura da Europa Oriental, apesar de manifestarem proclividades eróticas e predatórias. Imaginados, os seus "vampiros" são subprodutos evocativos de carne e osso de Curitiba ou dos seus arredores rurais. Na coletânea Rita, Ritinha Ritona, de 2005, surge uma espécie de metaficção na forma de uma despedida irônica aos seus vampiros dos anos 1960 dramatizada no conto "Adeus, Vampiro". Neste, a voz narrativa identifica, com toques psicológicos e nostálgicos, uma nova raça de vampiros vista como um "vampiro só de emoções e sentimentos. Um ladrão furtivo de almas solitárias. [...] Viciado, sim, na ciência da sedução, as manhas da traição, as artes da perversão, as dores secretas do amor, os mistérios da paixão" (Trevisan, 2005, p. 99-100). Aqui, o sangue vampiresco curitibano flui menos em termos metafóricos e mais em cenários psicologicamente cotidianos, se nutrindo da sexualidade, da decepção, da ilusão, e do mito capitalista ao lado da falsidade ubíqua tudo isso insidiosamente integrado nas interações sociais.

Apesar de não privilegiar uma teoria ou abordagem urbanista na linha teórica de Lefebvre, e sim dedicar-se ao espaço urbano evocado em Dalton Trevisan, o estudo de Andrew Gordus (1998) ${ }^{7}$ mapeia destramente tanto a própria cidade como o Vampiro. Gordus baseia a sua leitura no anonimato e na exploração associados às modernas metrópoles capitalistas, isto é, à vida mentalmente intensa (Georg Simmel), sobretudo em sociedades urbanas industriais com uma força operária poderosa de imigrantes e migrantes. Acima de tudo, o argumento de Gordus se relaciona, na linha de Simmel, com a história híbrida brasileira de desigualdade socioeconômica, provindo do autoritarismo implacável da sua cultura e manifestado por ritos e práticas culturalmente enraizados e muito reminiscentes de um passado rural, agricultural e feudal, repleto de códigos sociais e estruturas rígidas governados por uma oligarquia tirânica. Néstor García Canclini, em Culturas híbridas: estrategias para entrar y salir de la modernidad (1989), aponta para essa dicotomia inerente às cidades latinoamericanas, que desde o século XIX têm sido ligadas às ideias europeias de modernidade mas também afligidas pela realidade de um patriarcado inexorável, uma exclusão social e uma opressão hierárquica de classe (Holanda, 1936).

Noutras palavras, com o seu contexto sócio-histórico, apesar de uma modernidade materialista retumbante, a Curitiba de Dalton Trevisan

7 No seu estudo, "The vampiric and the urban space in Dalton Trevisan's $O$ vampiro de Curitiba", Andrew Gordus dedica a maior parte de seu trabalho à coletânea mencionada no título, mas, como ele declara na sua conclusão ao falar do espírito vampiresco de Curitiba: "Massificado, ele devora a cidade, apropriandose da cidade como sua. Em vez de ser conquistado, o espírito vampiresco tem florescido na cidade moderna brasileira, devendo muito da sua sobrevivência à cidade em si”' (Gordus, 1998, p. 25). 
ainda abriga vestígios sócio-históricos da sua experiência colonial. $\mathrm{Na}$ verdade, Curitiba ainda é referida como "província" em comparação às megalópoles de São Paulo (20 milhões de habitantes) e Rio de Janeiro (aproximadamente 8 milhões). Da perspectiva trevisaniana, pode-se declarar que Curitiba está presa entre uma mentalidade rural e uma modernidade urbana, vivendo uma gestalt conflituosa de entrelugar de passado e futuro. No seu ensaio seminal, Simmel comenta: "A metrópole exige do homem, sendo ele uma criatura perspicaz, uma quantia diferente de consciência do que a vida rural" (Simmel, 1969, p. 48). Simmel também fala da "intensificação de estimulação nervosa" no residente urbano. Nesse contexto, podemos perguntar se os planejadores urbanistas de Curitiba ficaram menos conscientes das possíveis ciladas subjacentes na encarnação metropolitana, especialmente perante um passado de cultura e economia rural? Será que o progresso da infraestrutura curitibana pode responder, de qualquer maneira, a essa dicotomia sócio-histórica? Será que o espaço mental do seu planejamento está sensível à volatilidade intensa da colisão entre códigos tradicionais e modernos estímulos urbanos? Será possível resolver isso? Talvez seja o que Dalton Trevisan afetiva e jocosamente proponha, no seu afinco de ridicularizar impiedosamente as fachadas de modernidade visível, de boa aparência e de decoro familiar.

Variações compulsivas e incisivas do mesmo tema, dramas empolgantes, repetitivos, refletivos, evocativos, mas também evolutivos, as mini-histórias de Trevisan são continuamente reconstruídas a fim de nos obrigar a nos reconhecer, a nos perscrutar, nós os seus hipócritas leitores, seletivamente cegos e muitas vezes emocionalmente desamparados, penando como almas sofridas e machucando o(a) outro(a), enquanto perambulamos no caos universal das relações humanas e desumanas (Vieira, 1984). Frequentemente, as narrativas na primeira pessoa tem um interlocutor - doutor, meritíssimo, você - que invariavelmente invoca o pensamento de um leitor/cidadão. Na seguinte citação do conto "Um Tal Tibinha", um "você" está implícito no "sabe como é", para arrastar e incluir o leitor a fim de sugerir que também ele passou pela mesma experiência: "Três anos de amor, essa coisa. A gente se acerta na cama. Sabe como é. Um faz tudo o que o outro gosta" (Trevisan, 2006, p. 27).

A repetição na obra de Trevisan não serve simplesmente para reenfatizar os mesmos dramas. Como o crítico Bruce F. Kawin afirma: "a repetição é um veículo para criar a sensação de infinidade" e "um presente contínuo nos ensina que 'permanência' é uma questão não de duração mas sim de intensidade e vivência” (Kawin, 1972, p. 183). Para responder ironicamente aos seus próprios críticos e àqueles leitores desconfiados 
que insensivelmente não percebem e assim não conseguem apreciar a sua afetividade inerente, Trevisan cria e recria numa "quase-repetição" a voz de um mesmo narrador/leitor, um joão-ninguém, pouco esclarecido, muito provinciano, um rude fala-barato, que escarnece a obra do autor, como no conto "Quem tem medo de vampiro?":

Há que de anos escreve ele o mesmo conto? Com pequenas variações, sempre o único João, a mesma bendita Maria. [...] Aqui o eterno João: "Conhece que está morta". Ali a famosa Maria: "Você me paga, bandido".

Quem leu um conto já viu todos. Se leu o primeiro já pode antecipar o último - antes mesmo que o autor. É a sua sagrada família de barata leprosa com caspa na sobrancelha, rato piolhento com gravata de bolinha, corruíra nanica com dentinho de ouro. Trincando broinha de fubá mimoso e bebendo licor de ovo? (Trevisan, 1992, p. 46).

Sim, aqui se transfigura a sua sagrada família, porém, não são os insetos ou animais em si mas os sentimentos nojentos e desconcertantes associados a essas criaturas que são projetados nos seus protagonistas e também em nós, nas nossas mentalidades. E essa autocrítica ou metacritica tão consciente e irônica inserida pelo próprio autor, revela a sua percepção nítida de si mesmo em comparação aos seus outros e, sobretudo, em relação à sua própria escrita como comportamento demoníaco inventado pela sua imaginação. A "coisa mental" que é Curitiba na mente do autor se transforma numa viagem sentimental, evocativa e saudosista mas simultaneamente perturbadora e interminável que, nas palavras de um narrador, parecido com o autor, não é a Curitiba "da Academia Paranaense de Letras, com seus trezentos milhões de imortais" (Trevisan, 1992, p. 7), mas a "Curitiba, que não tem pinheiros, essa Curitiba eu viajo. Curitiba, onde o céu azul não é azul, Curitiba que viajo. Não a Curitiba para inglês ver, Curitiba me viaja. [...] Curitiba sem pinheiro ou céu azul, pelo que vosmecê é - província, cárcere, lar -, esta Curitiba, e não a outra para inglês ver, com amor eu viajo, viajo, viajo" (Trevisan, 1992, p. 7, p. 9). Como é que um leitor não possa sentir a compaixão e carinho que Dalton Trevisan pelo "espaço vivido" e esquecido da sua cidade?

Como estados de alma camaleônicos, as narrativas trevisanianas de Curitiba são quase iguais, mas trazem diferenças segundo as circunstâncias. Miguel Sanches Neto comenta sobre essa quase repetição: “Os nomes se repetem assim como os dramas e os preconceitos. A repetição dos nomes é, dessa forma, um emblema do advento do eternamente idêntico. Os personagens estão dentro de uma existência cíclica inflexível" (Sanches Neto, 1996, p. 36). Por um lado, sendo diferentes mas parecidos, os perso- 
nagens e os cenários apontam para um status quo no espaço vivido por tais figuras marginalizadas. Por outro lado, as suas angústias se assemelham aos nossos momentos mais interiores ou íntimos - raramente revelados -, aos nossos sentimentos de insegurança e frequentemente desafortunados, relembrando que todos nós fazemos parte da comédia humana e infinita de uma Curitiba imaginada, isto é, uma cidade virtual e real (Zizek!, 2005), desvelando simultaneamente dramas urbanos e provincianos mas sempre universais. Como comenta Berta Waldman: "Esses discursos deslocados do real para a ficção compõem com breves pinceladas uma espécie de 'quadro vivo' concentrado no essencial, sem alçapões ilusionistas nem jogos de luz enganadores" (Waldman, 2009, s/n)

A Curitiba, cidade do passado, pode morrer, desaparecer ou se perder no meio da infraestrutura e ecologia modernas, mas não o seu drama, sobretudo com a evolução dos seus novos capítulos surgindo a cada ano - agora falando de drogas e crack, além dos problemas de álcool, estupros e outras brutalidades contínuas e incessantes. A obra de Trevisan, superatualizada com suas referências à periferia, às vilas perigosas, ao tráfico de drogas, na sua totalidade, já serve para uma eternidade. Objeto de uma narrativa composta de milhares de minicapítulos, a Curitiba ficcionalizada dramatiza no "espaço vivido" dos desfavorecidos um momento de angústia, sexo decadente, gestos violentos, alegria fugaz, perversões deliciosas, prazeres kitsch, a morte em vida, um carinho indiscreto - visões ou videoclipes da miséria humana que subitamente arrastam o leitor ou a leitora à sua própria intimidade, à sua subconsciência obscura e tenebrosa, onde gradualmente se descobre a diferença entre comportamento exterior, social, sexual, político, emocional e as verdades interiores do seu próprio ser/self/alma/mente.

Para Dalton Trevisan, Curitiba é simbólica e figurativamente o fim da linha de um coração-bonde dilacerado, o fim de um mundo psicológico que se encontra em toda parte do mundo - o pico na veia, a faca no coração. Dalton Trevisan está colocando em cena uma Curitiba de alma, uma Curitiba que viaja pela alma dele e pelas almas dos seus personagens e leitores mortais, nos seus momentos mais aflitos, carnais, e emocionais.

Nessa linha, a sua obra pode ser também apreciada pelo seu registro dramático e performativo. Em outras palavras, pelo potencial no ser humano de gerar ou despertar uma autoconsciência, manifestado em personagens vulneráveis e abusadas, percepções e revelações que imediatamente são transferidas para o leitor, assim apontando que, na sua criação de um mundo imaginário curitibano, Dalton Trevisan está nos lendo e nos guiando no processo de penetrar e melhor entender a nossa consciência 
humana, os nossos pensamentos, as nossas hesitações, os nossos segredos, os nossos atos bons e maus, os nossos comportamentos honestos e falsos, as nossas violências duras e doces, os nossos pecados escondidos e dificilmente autorrevelados ou enfrentados. E nas suas imagens-pensantes na forma de haicais, na sua coleção $A h$, é? mini-stórias temos esse exemplo de uma cena violenta e íntima: "Guerra conjugal: as mil e uma batalhas da minha, da tua, da nossa Ilíada doméstica" (Trevisan, 1994, p. 103). E do longo conto “Virgem louca, loucos beijos" surge uma descrição consciente e performativa: "O senhor distinto, gravata e pasta. Ao tirar a roupa, ai que nojento. Ainda bem, nada consegue" (Trevisan, 1980, p. 47).

Sejam cenas domésticas cotidianas, banais, ousadas, chocantes, horríveis, brutais, tristes, eróticas, cruéis ou perversas, as diversas histórias urbanas de Dalton Trevisan representam uma grande parte ou, em certos casos, uma microparte das nossas próprias experiências urbanas e dos nossos pensamentos, que sempre emergem ou se manifestam de uma forma ou outra nas suas narrativas, chamando a nossa atenção aos obstáculos, aos percalços, às peripécias, às perversões, e às provocações que a existência humana coloca na nossa frente, especialmente no espaço vivido e terreno da cidade.

Comparado a Anton Tchekhov, Franz Kafka, Edgar Allan Poe, e outros, Dalton Trevisan se distingue como mestre de conto urbano pelo seu talento de nítida precisão, concisão inovadora, densidade mordaz evocada pela famosa "unidade de efeito" tão querida à definição do gênero do conto que Edgar Allan Poe ofereceu em seu ensaio seminal "A filosofia de composição" (Poe, 1846). Porém, para além dos elogios formais e temáticos controversos, Dalton Trevisan mergulha a sua pena como um fio de prumo é mergulhado nas profundezas do mar, mas aqui simbolicamente nas profundezas funestas e perigosas da existência urbana, assim encenando o lado nefasto do homem e da cidade, não por motivos sensacionalistas, mas pela compulsão de evocar o que é escondido nas margens e sobretudo o que a gente esconde nas nossas imaginadas noites vampirescas que perturbam as nossas almas e mentes noite e dia. Os seus vampiros não vivem segregados, não viajam de longe para Curitiba a fim de atacar as pessoas, mas moram, sim, subjacentes aos escondidos, pertencendo a Curitiba, como todos nós pertencemos pelo menos a um lugar: "no fundo de cada filho de família/dorme um vampiro" ("Balada do vampiro", Trevisan, 1992, p. 21). Com os desejos carnais e às vezes violentos, esse conto referido é uma denúncia irônica do patriarcalismo vigente. Esses vampiros psicologicamente mascarados manifestam diversos comportamentos sociais, indubitavelmente enraizados na cultura autoritariamente estru- 
turada pela sociedade. Esses vampiros fomentam e provocam apreensões perante as suas aparições assustadoras e ataques insensíveis, como aves de rapina, descendo no ambiente urbano silenciosa e velozmente sobre as pessoas, família, amantes, amigos, vizinhos, e inimigos. Da coletânea Crimes de paixão (1978), no conto "Dá uivos, Ó porta, Grita, Ó Rio Belém", emerge uma referência ao contista observando com pena a galeria maldosa, frenética mas vulnerável, da comédia humana que percorre a sua cidade: "Atrás da cortina, vigiando a rua, o contista se repete: Pobre Maria, pobre João que, em toda casa de Curitiba, se crucificam aos beijos na mesma cruz" (Trevisan, 1992, p. 28-32).

É sabido que surgiram, no decorrer das últimas décadas, e cada vez mais, adaptações das narrativas trevisanianas para o teatro. Essa manifestação artística confirma o aspecto intrinsecamente teatral da obra de Dalton Trevisan e nos leva a sublinhar o conceito da sua arte como performativa - não somente em termos tradicionais de teatro, mas chamando a nossa atenção para o lado performativo da linguagem dos seus atores e das nossas próprias existências cotidianas, repletas de papéis pré-escritos e feitos ou construídos.

Segundo o estudioso Richard Schechner (2002), em Performance studies: an introduction, o performativo sugere a circunstância em que nós estamos fazendo um papel e estamos conscientes disso porque reconhecemos que as nossas vidas estão estruturadas por modos ou códigos de comportamento estabelecidos e socialmente sancionados, como se toda a atividade humana pudesse ser identificada como performativa, já que se trata de atividades acompanhadas por uma autoconsciência alerta e perspicaz. Obviamente, como muitas das personagens trevisanianas, podemos agir sem pensar, sim, mas quando pensamos bem sobre as nossas ações, quando nós nos examinamos honestamente, isso estimula uma percepção, uma autoconsciência, uma qualidade que podemos delinear como "performativa", porque, assim, reconhecemos criticamente por que nós nos comportamos de uma certa maneira. No nosso entender, a obra de Trevisan manifesta altamente esse conceito performativo para os seus leitores, porque como autor ele reconhece que nem todos os seus personagens ou leitores se apercebem ou têm consciência das inúmeras repercussões sutis e frequentemente vis de suas próprias ações. $\mathrm{O}$ "espaço vivido" perfilado por Dalton Trevisan é um terreno que provoca uma aguda consciência em que a leitora se apercebe do aspecto regressivo e destrutivo das relações humanas, sobretudo daquelas sobrevivendo num espaço não ecologicamente correto ou moderno.

Estamos seguindo uma "vida líquida", como diz o sociólogo polonês Zygmunt Bauman, em que a existência em si não é mais estável, nem o sen- 
tido de identidade - aliás pensa-se mais em identificações. Nesse ambiente, o medo e a insegurança dominam a vida urbana, numa modernidade líquida em que "os bairros centrais são valorizados e tornam-se objeto de grandes investimentos urbanísticos, [enquanto] outras áreas são corroídas pela degradação e tornam-se marginais" (Bauman, 2005, p. 8-9). Parece que os "bairros centrais" de Curitiba podem aproveitar os investimentos de um urbanismo moderno enquanto as "vilas" ficam desamparadas.

Criticado por enfocar as suas narrativas, em sua maior parte, na classe média e baixa, Dalton Trevisan decidiu se dedicar à condição humana dessa camada a fim de mostrar como o seu comportamento é resultado de uma estrutura sociopolítica que prejudica os menos privilegiados. Porém, ao mesmo tempo, e indiretamente, ele está aludindo a todas as classes, porque os desejos, os pecados, as angústias, e as necessidades do nível social menos afortunado são humanas e também relevantes a todos. Porém, no conto "Quem tem medo do vampiro?", para abordar a assunto de classe, Dalton Trevisan de novo recorre ao seu joão-ninguém, que se dirige ao autor, como se aquele fosse um fala-barato, membro de um público crítico da sua obra, com o propósito de levantar uma questão tão inerente à sua arte: "Pérfido amigo, usará no próximo conto a minha, a tua confidência na secreta mesa de bar. Cafetão de escravas brancas da louca fantasia, explora a confiança da nossa gente humilde. Ó maldito galã de bigodinho e canino de ouro, por que não desafia os poderosos do dia: o banqueiro, $\mathrm{o}$ bispo, o senador, o general?" (Trevisan, 1992, p. 46-47).

Essa citação ilustra a alta consciência e sensibilidade de Dalton Trevisan em relação às repercussões da sua obra. Aqui, sutilmente ele está sugerindo que essa gente humilde tem muito para nos dizer por meio dos dramas das suas vidas. A opção de privilegiar "gente humilde", em vez dos poderosos banqueiros, bispos, senadores e generais, faz parte da estética trevisaniana, porque as dimensões escondidas, as vergonhas políticas, a economia injusta, a religião insensível, e o governo autoritário (daquele momento) estão insidiosamente refletidos nas almas das suas personagens abandonadas. Além disso, enquanto Trevisan emprega uma forma narrativa em que, na maior parte das vezes, parece não existir narrador, por causa do seu uso de diálogo e do elíptico, o autor faz com que os seus personagens se dramatizem por si mesmos sem uma voz (autor) itária. Portanto, o processo performativo, marcando a consciência sobre comportamentos, eleva a obra a um nível superior de percepção e em seguida desperta a consciência do espectador/leitor.

Em conclusão, Dalton Trevisan se mostra performativo como artista, porque retrabalha conscientemente os contos no "espaço vivido" 
curitibano, vibrante, mas prejudicado pela sua crua realidade. Desde as suas primeiras publicações, Dalton Trevisan e suas editoras têm sido cúmplices na sua visão estética e comercial para lançar e divulgar a sua obra, sobretudo na junção das palavras do escritor com poderosas imagens nas capas e nas contracapas, e até nas páginas no meio da prosa - reproduções de velhas fotografias eróticas, gravuras, arte litográfica, e desenhos, isto é, um álbum de uma cultura urbana que suscita "imagens-pensantes" segundo Walter Benjamin. Essa prática gráfica consistente sugere duas técnicas que contribuem para uma consciência intensificada sobre o espaço social vivido e frequentemente esquecido por planejadores, mesmo os mais sensíveis, e onde as interações desesperadas dos seus protagonistas se inflamam. A predominância de gravuras transmite uma qualidade Rorschach às imagens, que, uma vez decifradas, evocam psiques angustiadas, necessitando melhor assistência social e pública.

Com as velhas fotografias, o leitor é obrigado a reconhecer formas de práticas eróticas e cruéis contra mulheres e simultaneamente o falso decoro que ainda se manifesta devido aos valores distorcidos de um passado colonialista. A persistência e a universalidade dessas imagens também comunicam uma ressonância arquetípica que transcende os limites geográficos de Curitiba e do Brasil na direção de uma condição humana aflita. Essa universalidade é transmitida por via de uma gama de fotógrafos, gravadores, pintores e desenhistas que foram selecionados para comunicar o caos urbano, crimes e injustiças sociopolíticas proliferando atrás de portas fechadas, isto é, violências clandestinas, cumplicidades voyeurísticas e as vidas fim-da-linha, se danando agressivamente dentro dos espaços vividos de cidades, particularmente durante períodos de agudas crises revolucionárias, repressivas e econômicas. Alguns desses artistas são: José Guadalupe Posada e suas "calaveras" simbolizando as catástrofes e revoluções do México; Georg Grosz e sua visão mordaz e caótica da Alemanha Nazista; e Poty, nativo de Curitiba, com seus desenhos violentos da vida social local. As obras desses artistas têm sido adaptadas para sublinhar na cidade os "espaços representacionais" de distorção social que Dalton Trevisan tem acentuado dramaticamente. Nesse sentido, o impulso narrativo de Dalton Trevisan desperta consciência sobre as práticas espaciais e sociais que precisam ser mais conectadas ao espaço mental dos planejadores urbanos. Aqui, com o acoplamento modernista de palavra e imagem, para Dalton Trevisan, estes dois gêneros, ficção e imagem, se juntam para montar paradigmas socioculturais que são arcaicos, duradouros e deploráveis, estruturas que 
têm prejudicado, para muitos curitibanos, o acesso multidimensional ao progresso infraestrutural e ecológico e sobretudo a um padrão de vida melhor para o espaço vivido da cidade.

\section{Referências}

BAUMAN, Zygmunt (2005). Confiança e medo na cidade. Rio de Janeiro: Zahar. BENJAMIN, Walter (2008). One-way street and other writings. Tradução de J. A. Underwood. London: Penguin.

BRUGMANN, Jeb (2009). Welcome to the urban revolution: how cities are changing the world. New York: Bloomsbury.

CANCLINI, Néstor García (1989). Culturas híbridas: estrategias para entrar y salir de la modernidad. Ciudad de México: Grijalbo.

GILLOCH, Graeme (1996). Myth \& metropolis: Walter Benjamin and the city. Cambridge, UK: Polity.

GORDUS, Andrew (1998). The vampiric and the urban space in Dalton Trevisan's O vampiro de Curitiba. Rocky Mountain Review, Spring, p. 13-26.

HOLANDA, Sérgio Buarque de (1936). Raízes do Brasil. Rio de Janeiro: José Olympio. KAWIN, Bruce (1972). Telling it again and again: repetition in literature and film. Ithaca: Cornell University Press.

LEFEBVRE, Henri (2005). The production of space. Tradução de Donald Nicholson-Smith. Oxford: Blackwell.

POE, Edgar Allan (1846). The philosophy of composition. Graham's Magazine, Philadelphia, v. 28, n. 4, p. 163-167.

SANCHES NETO, Miguel (1996). Biblioteca Trevisan. Curitiba: Editora UFPR.

SCHECHNER, Richard (2002). Performance studies: an introduction. New York: Routledge.

SIMMEL, Georg (1969). The metropolis and mental life. In: SENNETT, Richard (ed.). Classic essays on the culture of cities. New York: Appleton-Century-Crofts.

TREVISAN, Dalton (1974). O vampiro de Curitiba. São Paulo: Civilização Brasileira, José Olympio e Três.

(1979). Novelas nada exemplares. 5 ed. Rio de Janeiro: Record.

(1980). Virgem louca, loucos beijos. Rio de Janeiro: Record.

(1992). Em busca de Curitiba perdida. Rio de Janeiro: Record.

(1994). Ah, é?: ministórias. Rio de Janeiro: Record.

(1997). 234: ministórias. Rio de Janeiro: Record.

(2002). Pico na veia. Rio de Janeiro: Record.

(2005). Rita, Ritinha Ritona. Rio de Janeiro: Record.

(2006). Macho não ganha flor. Rio de Janeiro: Record.

VIEIRA, Nelson (1984). Narrative in Dalton Trevisan. Modern Language Studies, v. 14, n. 1, p. 11-21. 
WALDMAN, Berta (2009). Faca no coração: uma leitura da obra de Dalton Trevisan. Minas Gerais: Suplemento Literário, v. 1321, p. 5-7.

ZIZEK! (2005). Direção: Astra Taylor. Produção: Lawrence Konner. Canada/USA: Zeigeist Films. 1 DVD (71 minutos).

Recebido em dezembro de 2012. Aprovado em abril de 2013.

\section{resumo/abstract}

\section{Espaço vivido e espaço mental: Dalton Trevisan e a dicotomia social do urbanismo curitibano}

Nelson H. Vieira

Este ensaio trata dos contos de Dalton Trevisan e da cidade de Curitiba dentro do contexto do urbanismo como "espaço vivido", para usar a terminologia de André Lefebvre, a fim de entender a dicotomia social entre uma mentalidade rural e uma modernidade urbana. Contrastando os elogios de Curitiba como "cidade verde" com os cenários tragicômicos e nefastos perfilados nas narrativas trevisanianas, este estudo aponta para os vestígios sócio-históricos do passado colonial da cidade e como aquela experiência social ainda marca o comportamento local. Além de mostrar como os contos trevisanianos tendem para o universal, por causa do seu diálogo altamente consciente com o leitor e apesar do seu enfoque regional, sublinhamos como a contradição entre o sardônico e o afetivo revela o lado sentimental mas perturbador dessa comédia humana. Com alusões aos seus contos e haicais como as "imagens-pensantes" (de Walter Benjamin), esta leitura também dá enfoque ao aspecto performativo da sua obra, que serve para desmascarar a hipocrisia escondida nas consciências urbanas dos personagens e dos seus próprios leitores. Contra o espaço mental formulado por planejadores-urbanistas, vê-se como o "espaço vivido" pelos habitantes não coaduna bem com a imagem ecológica promulgada. Porém, no meio da evocação vampiresca da cidade por parte do autor, sempre surge uma dose de compaixão e saudade que, afinal de contas, desafia a imagem de Dalton Trevisan como crítico mordaz e insensível perante a sua Curitiba.

Palavras-chave: Curitiba, Dalton Trevisan, espaço, contos. 


\section{"Lived and Mental Space: Dalton Trevisan and the Social Dichotomy of Curitiba's Urbanism"}

\section{Nelson H. Vieira}

This essay deals with the short stories of Dalton Trevisan and the city of Curitiba within the context of urbanism as "lived space", using André Lefebvre's terminology, with the aim of understanding the social dichotomy between a rural mentality and an urban modernity. By contrasting the many praises that Curitiba has received as a "green city" with tragic-comic and ominous scenarios played out in Trevisan's narratives, this study points to the socio-historic vestiges of its past as a colonial city and how that social experience still marks local behavior. Besides illustrating how Trevisan's short stories tend toward the universal, due to their highly conscious dialog with the reader and in spite of its regional focus, we underscore how the contradiction between the sardonic and the affective uncovers the sentimental yet disturbing side of this Human Comedy. With allusions to his stories and haikus as "thinking images" (coined by Walter Benjamin), this reading also emphasizes the performative aspect of his work that serves to unmask the hidden hypocrisy within the urban consciences of his protagonists and those of his readers. In opposition to the mental space formulated by urban planners, one sees how "space lived" by its inhabitants does not tie well into the highly promulgated ecological image of the city. However, in the midst of the city's vampiresque evocation emanating from the author himself, there always emerges a dose of compassion and nostalgia which in the final analysis challenges Dalton Trevisan's image as a mordant and insensitive critic of his Curitiba.

Keywords: Curitiba, Dalton Trevisan, space, short stories. 